\begin{tabular}{|l|l|}
\hline JURNAL ABDI MASYA & $\begin{array}{l}\text { Volume 1 Nomor } 3 \\
\text { November 2021 } \\
\text { pe 132-136 } \\
\text { E-ISSN : 2774-2849 }\end{array}$ \\
P-ISSN : 2774-2881 & Website: https://jurnal.sttw.ac.id/index.php/abma/about \\
\hline
\end{tabular}

\title{
PELATIHAN ROBOT PENGIKUT GARIS (LINE FOLLOWER) UNTUK SISWA SMK BATIK 2 SURAKARTA DI PRODI TEKNIK ELEKTRONIKA STT "WARGA" SURAKARTA
}

\author{
LINE FOLOWER ROBOT TRAINING FOR STUDENTS OF VOCATIONAL SCHOOL OF \\ BATIK 2 SURAKARTA IN ELECTRONICS ENGINEERING PROGRAM \\ STT "WARGA" SURAKARTA \\ S. Marwanto ${ }^{{ }^{*}}$, Suharjanto ${ }^{2}$, Pius, S.W ${ }^{3}$, Aris T.R ${ }^{4}$ \\ 1,2,3,4Program Studi Teknik Elektronika, Sekolah Tinggi Teknologi “Warga” Surakarta, Surakarta, Indonesia \\ *Emai: marwanto@sttw.ac.id
}

\begin{abstract}
ABSTRAK
Pembelajaran robotik mendukung siswa untuk mendapatkan materi yang saling terintegrasi antara subyek pelajaran Science (sains), Technology (teknologi), Engineering (teknik), dan Mathematics (matematika). Robotika adalah perpaduan berbagai disiplin ilmu, khususnya mekanik, elektronik dan komputer. Jenis robot yang dipilih untuk pelatihan adalah robot Line Follower karena pembuatan robot ini tidak terlalu rumit sehingga diharapkan siswa dapat menguasai dengan cepat teknik pembuatannya. Sasaran dari program Pengabdian Kepada Masyarakat ini adalah siswa-siswi SMK Batik 2 Surakarta dan telah terlaksana dengan baik dan lancar pada hari Kamis, 11 Februari 2021, bertempat di Laboratorium Komputer dan Laboratorium Digital, Prodi Teknik Elektronika, Kampus Sekolah Tinggi Teknologi "Warga" Surakarta. Peserta pelatihan berjumlah 10 orang siswa-siswi SMK Batik 2 Surakarta dengan didampingi dua orang guru pendamping. Hasil dari pelatihan ini, semua peserta dapat merakit dan memprogram sendiri robot line follower.
\end{abstract}

Kata kunci: pelatihan, robot, robotik, pengikut garis, line follower.

\section{Submit: 14 September Accepted: 12 November} Published: 26 November 2021

\section{PENDAHULUAN}

Robotika adalah perpaduan berbagai disiplin ilmu, khususnya mekanik, elektronik dan komputer. Dengan adanya perkembangan teknologi robotika yang pesat, bangsa Indonesia dituntut untuk mampu menguasai pengetahuan tentang robotika agar generasi penerus mampu mengembangkan robot untuk menghadapi persaingan global.

Saat ini robotika mempunyai peran yang cukup signifikan terhadap perubahan metode pembelajaran di sekolah. Siswa tidak hanya bisa menyerap pelajaran melalui teori yang diajarkan di kelas, tetapi juga bisa langsung mempraktikkannya lewat media robot. Dengan melihat fakta tersebut maka pembelajaran robotika perlu dikenalkan sejak dini kepada siswa dari mulai SD, SMP maupun SMA/SMK. 
Pembelajaran robotik juga mendukung siswa untuk mendapatkan materi yang saling terintegrasi antara subyek pelajaran Science (sains), Technology (teknologi), Engineering (teknik), dan Mathematics (matematika) atau dikenal dengan istilah STEM [1]

Salah satu jenis robot yang paling sederhana dan sering digunakan sebagai materi awal pembelajaran robotik adalah robot pengikut garis atau line follower. Robot pengikut garis adalah sebuah robot yang dapat mengikuti garis secara otomatis. Garis yang dimaksud adalah garis berwarna hitam diatas permukaan berwarna putih atau sebaliknya [2]. Sensor pendeteksi garis yang digunakan dalam robot pengikut garis biasanya mendasarkan pada prinsip pemantulan cahaya untuk membedakan warna garis dengan latar belakangnya. Sensor untuk cahaya tampak yang umum digunakan adalah LDR (Light Depending Resistance), sedangkan untuk cahaya inframerah adalah transistor cahaya (phototransistor) dan dioda cahaya (photodiode) [3].

Materi pemrograman juga diperlukan dalam pembelajaran robotik robot pengikut garis. Kinerja robot pengikut garis juga ditentukan oleh runtutan program yang dimasukkan ke dalam mikrokontroler. Mikrokontroler adalah pusat dari semua instruksi masukan maupun keluaran dari keseluruhan fungsi robot [4]. Robot pengikut garis menjadi salah satu hal sederhana yang dipelajari saat kita berbicara dalam bidang robotika, dikarenakan algoritma yang sederhana dan sangat mudah untuk dipelajari, dibuat, dan dikembangkan.

Berdasarkan uraian tersebut, Prodi Teknik Elektronika mengadakan kegiatan berupa pelatihan robot pengikut garis yang diikuti oleh siswa SMK Batik 2 Surakarta.

\section{METODE}

Pelaksanaan kegiatan pelatihan robot pengikut garis untuk siswa SMK Batik 2 Surakarta di Prodi Teknik Elektronika dilaksanakan secara tatap muka langsung antara pengajar dengan peserta pelatihan dalam waktu 1 hari di Laboratorium Komputer dan Laboratorium Digital Prodi Teknik Elektronika. Pelatihan robot pengikut garis untuk siswa SMK Batik 2 Surakarta dibagi dalam 3 tahap atau sesi, yaitu:
a. pengenalan perangkat keras (hardware) robot pengikut garis,
b. pengenalan perangkat lunak (software) robot pengikut garis, dan
c. pembuatan/perakitan robot pengikut garis.

\section{HASIL DAN PEMBAHASAN}

Pelaksanaan Program Pengabdian Kepada Masyarakat (PKM) berupa kegiatan pelatihan robot pengikut garis untuk siswa SMK Batik 2 Surakarta di Prodi Teknik Elektronika telah dilaksanakan pada hari Kamis, 11 Februari 2021 dengan diikuti peserta dari siswa-siswi SMK Batik 2 Surakarta sebanyak 10 orang peserta dengan 2 orang guru pendamping. Daftar nama peserta dan guru pendamping disajikan dalam tabel 1.

Tabel 1. Daftar Peserta dan Guru Pendamping

\begin{tabular}{clc}
\hline No & \multicolumn{1}{c}{ Nama } & Keterangan \\
\hline 1 & Nadila Devi K & Peserta \\
2 & Aiza Rahayu & Peserta \\
3 & Inanda Ridva T & Peserta \\
4 & Arum Sintia & Peserta \\
5 & Muhammad Chafidz A & Peserta \\
6 & Hanggoro Bayu Seto & Peserta \\
7 & Muhammad Sidiq & Peserta \\
\hline
\end{tabular}




\begin{tabular}{clc}
\hline No & \multicolumn{1}{c}{ Nama } & Keterangan \\
\hline 8 & Rendy Hermawan S & Peserta \\
9 & Ivan Noviandra & Peserta \\
10 & Ananda Arsyad S & Peserta \\
11 & Fadila Aini Atista, S.Pd & Guru Pendamping \\
12 & Fera Aulia'a Wati, S.Pd & Guru Pendamping \\
\hline
\end{tabular}

Laboratorium Komputer dan Laboratorium Digital di Progdi Teknik Elektronika menjadi tempat untuk proses pelatihan robot pengikut garis. Laboratorium Komputer digunakan untuk pelaksanaan sesi pertama dan kedua yaitu pengenalan hardware dan pengenalan software robot pengikut garis. Laboratorium Digital digunakan untuk pelaksanaan sesi ketiga yaitu pembuatan/perakitan robot pengikut garis.

Dalam kegiatan pengenalan hardware, disampaikan materi pengenalan perangkat keras (hardware) robot pengikut garis secara terperinci, yaitu:
a. garis lintasan;
b. sensor garis;
c. mikrokontroler;
d. USB ASP AVR Programmer;
e. motor driver;
f. motor dc, gearbox dan roda; dan
g. chasis robot line follower.

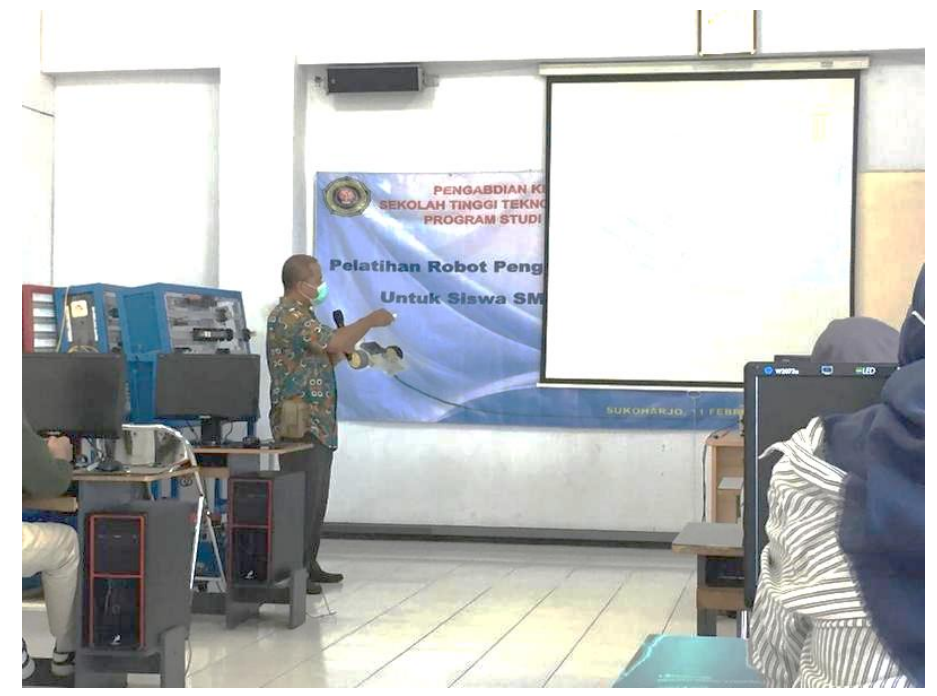

Gambar 1. Pengenalan perangkat keras robot pengikut garis

Dalam kegiatan pengenalan software, disampaikan materi pengenalan perangkat lunak (software) robot pengikut garis, yaitu:
a. pemrograman dengan bahasa $\mathrm{C}$;
b. software Code Vision AVR Programmer;
c. software simulator Proteus; dan
d. software Khazama AVR Programmer. 


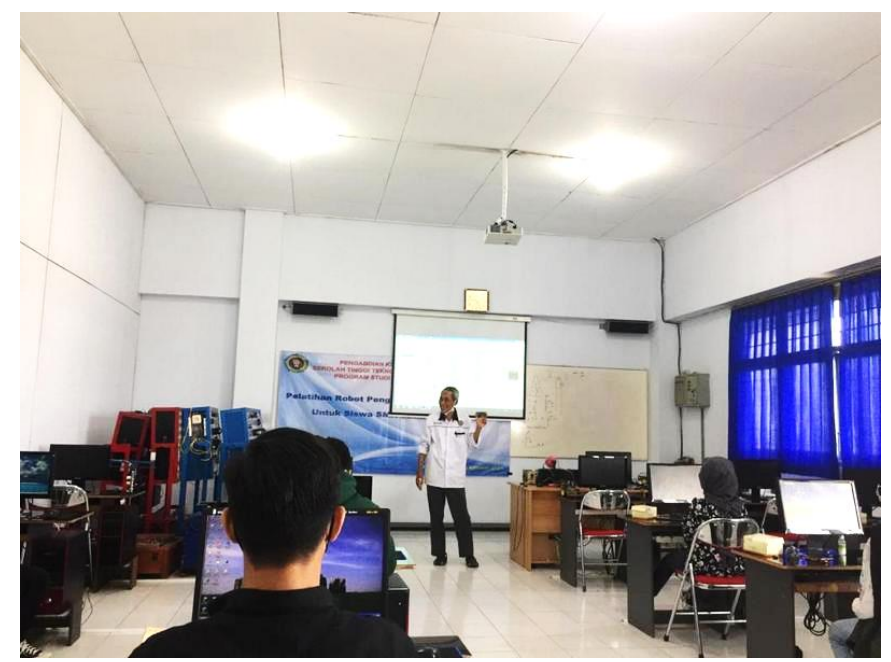

Gambar 2. Pengenalan perangkat lunak robot pengikut garis

Dalam kegiatan pembuatan/perakitan robot pengikut garis, peserta dibagi ke dalam 5 kelompok, sehingga dalam satu kelompok terdiri dari dua orang peserta. Dalam pembuatan/perakitan robot pengikut garis, dilaksanakan kegiatan memasukkan (download) program robot line follower ke dalam IC AVR ATMega16 menggunakan minimum sistem AVR ATMega16, USB ASP AVR Programmer dan Khazama AVR Programmer; dan merakit hardware robot pengikut garis ke chasis robot pengikut garis dengan cara memasang semua modul ke atas chasis dan melakukan penyambungan dengan menggunakan kabel konektor.

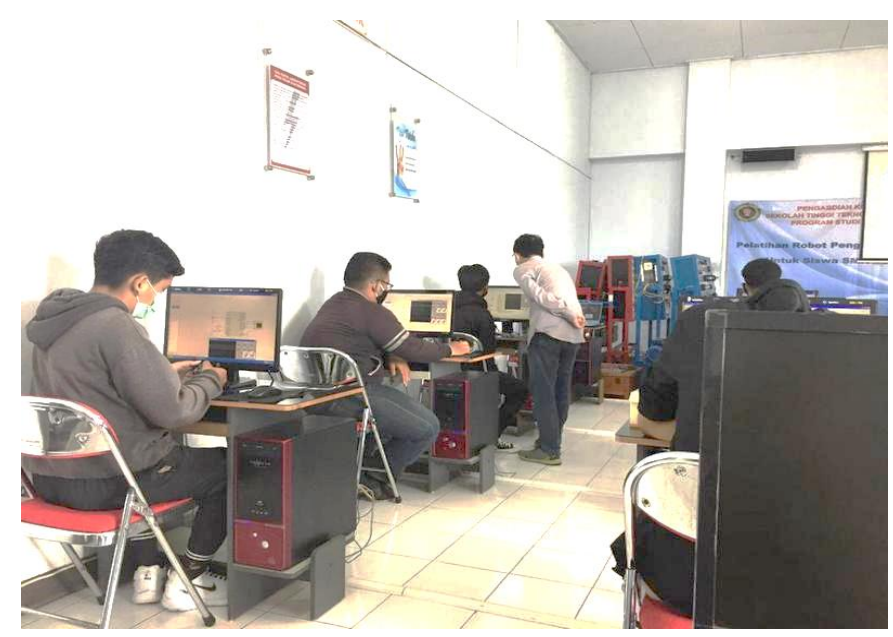

Gambar 3. Latihan software robot pengikut garis

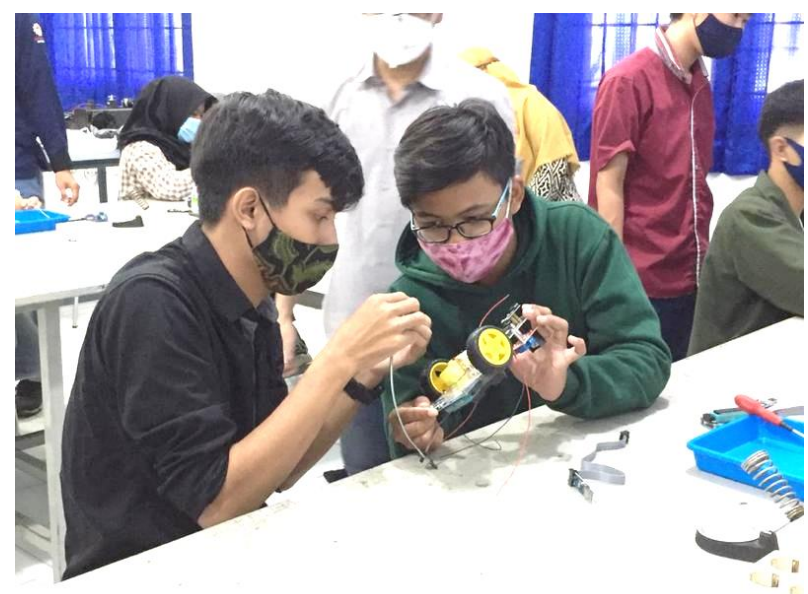

Gambar 4. Perakitan Robot pengikut garis 


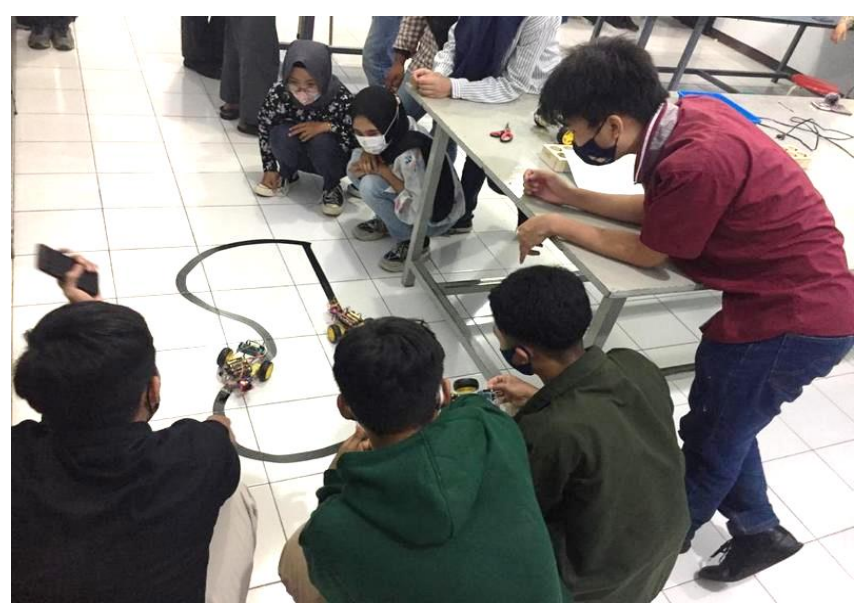

Gambar 5. Hasil perakitan robot pengikut garis

Dari lima kelompok perakit robot pengikut garis, semuanya berhasil menyelesaikan tugasnya dan robot pengikut garis dapat mengikuti garis yang telah disiapkan.

\section{KESIMPULAN}

Kegiatan pengabdian kepada masyarakat telah dilaksanakan dalam bentuk pelatihan robot pengikut garis untuk siswa SMK Batik 2 Surakarta di Prodi Teknik Elektronika STT "Warga" Surakarta. Kegiatan pelatihan robot pengikut garis ini dapat membantu siswa SMK Batik 2 Surakarta dalam memahami dan mempelajari ilmu mekanik, elektronik dan komputer yang diaplikasikan ke dalam ilmu robotik, khususnya robot pengikut garis.

\section{UCAPAN TERIMA KASIH}

Terima kasih yang sebesar besarnya kami sampaikan kepada Kepala SMK Batik 2 Surakarta beserta guru-guru, Ketua Sekolah Tinggi Teknologi "Warga" Surakarta, rekan rekan Dosen Prodi Teknik Elektronika Sekolah Tinggi Teknologi "Warga" Surakarta, HMJ Jurusan Teknik Elektronika, seluruh peserta pelatihan, dan juga pada semua pihak yang telah membantu terlaksananya kegiatan pengabdian ini.

\section{DAFTAR PUSTAKA}

[1] edukasi.kompas.com. Kalkulator dan Praktik Pembelajaran STEM di Indonesia. 28/9/2018.

[2] Fahmi Diyati. Rancang Bangun Robot Line Follower Berbasis Cahaya Tampak. Universitas Airlangga, Surabaya, 2016.

[3] Akash, S., Bibek Kabi, Mr. S.Karthick. Implementing a Line Tracing Robot as an effective Sensor and Closed Loop System. International Journal of Recent Trends in Engineering: Academy Publisher, Volume 2 Nomor 7 Tahun 2009, hal. 104 107.

[4] Anggoro Mukti, Oky Dwi Nurhayati, Eko Didik Widianto. Rancang Bangun Sistem Kontrol Robot Line Follower Menggunakan Logika Fuzzy. Jurnal Teknologi dan Sistem Komputer: Universitas Diponegoro, Volume 3 Nomor 4 Tahun 2015, hal. 536 - 543. 